\title{
Physician variation in the management of patients with atrial fibrillation
}

\author{
Gregory Y H Lip, John Zarifis, Robert D S Watson, D Gareth Beevers
}

\begin{abstract}
Objective-To investigate variations in the management of patients with atrial fibrillation among consultant physicians. Design-Questionnaire survey. Subjects-Consultant physicians in England, Wales, and Scotland.

Results-214 consultant physicians (88 cardiologists and 126 non-cardiologists) were surveyed between May and July 1994. Most physicians $(47 \cdot 7 \%)$ reported that they saw one to five patients with atrial fibrillation weekly. Some $52 \%$ of cardiologists and $40 \%$ of non-cardiologists considered that the main factor influencing their decision of whether or not to anticoagulate was the clinical history-that is, heart failure, valve disease, or stroke.
\end{abstract}

When encountering a patient admitted acutely with new onset atrial fibrillation, significantly more cardiologists $(66 \%$ v $\left.52 \%, \chi^{2}=6.89, P=0.03\right)$ would immediately start anticoagulant treatment, most favouring intravenous heparin. Most physicians would also introduce antiarrhythmic treatment or digoxin, but more cardiologists would attempt immediate pharmacological $(39 \% v 18 \%$ of non-cardiologists, $\mathbf{P}<0.001$ ) or later electrical $\left(86 \%\right.$ v 69\%, $\left.\chi^{2}=11 \cdot 7, P=0.003\right)$ cardioversion to sinus rhythm, while noncardiologists tended to prefer "rate control" with digoxin. Although many physicians would not continue antiarrhythmic treatment post-cardioversion, more cardiologists than non-cardiologists would do so (the commonest choice being class III agents) $(31 \% v 17 \%, P=0.04)$. Fewer non-cardiologists would continue anticoagulant treatment post-cardioversion $\left(27 \% v 69 \%\right.$ of cardiologists, $\chi^{2}=39.8$, $P<0.0001)$. When treating patients with atrial fibrillation, decisions about anticoagulation were usually related to the perceived relative risk of thromboembolism versus haemorrhage derived for each of six case management scenarios in the questionnaire. There was, however, general agreement between cardiologists and non-cardiologists in the use of antithrombotic treatment in the management of lone atrial fibrillation, paroxysmal atrial fibrillation, and patients with atrial fibrillation and mitral valve disease or thyrotoxicosis.
Conclusion-There is considerable variation in the management of atrial fibrillation, with more cardiologists than non-cardiologists considering cardioversion to sinus rhythm (and the use of antiarrhythmic and anticoagulant treatment post-cardioversion) and thromboprophylaxis with anticoagulation. Guidelines on the management of this common arrhythmia are clearly required.

(Heart 1996;75:200-205)

Keywords: atrial fibrillation; physician variation; questionnaire survey

Atrial fibrillation is a common arrhythmia with different aetiologies, clinical presentations, and therapeutic options. Ideally, the management of atrial fibrillation should follow three phases: a search for an underlying cause with appropriate investigations; control of the arrhythmia and the reduction of thromboembolic risk; and finally, consideration of cardioversion to sinus rhythm.

We have observed that there are wide variations in management strategies of this common arrhythmia. In a recent prospective survey of acute admissions with atrial fibrillation to a district general hospital, there was suboptimal application of standard investigations, a reluctance to start anticoagulant treatment, or to consider electrical or pharmacological cardioversion. ${ }^{1}$ In addition, retrospective studies have shown that many patients with atrial fibrillation were not receiving anticoagulation despite the absence of contraindications. ${ }^{23}$

The variations in investigations, therapeutic use of antiarrhythmic treatment, and prophylactic use of anticoagulant treatment may be a reflection of a lack of consensus on the optimal management of atrial fibrillation among physicians. For example, in a survey of 134 clinicians Chang et $a l^{4}$ reported considerable variation in the use of anticoagulant treatment in atrial fibrillation. However, that survey was published before the publication of several large randomised controlled trials of the use of warfarin or aspirin, or both, as thromboprophylaxis against stroke in patients with atrial fibrillation. ${ }^{5-7}$

To investigate further the extent of variation in management of atrial fibrillation and to determine whether clinicians make treatment
Dr G Y H Lip, University Department of Medicine, City Hospital, Dudley Road, Birmingham B18 7QH

Accepted for publication 25 July 1995 
Table 1 Summary of cases of patients with atrial fibrillation

\begin{tabular}{|c|c|c|c|c|c|}
\hline $\begin{array}{l}\text { Case } \\
\text { no }\end{array}$ & $\begin{array}{l}\text { Age } \\
\text { (years) }\end{array}$ & Sex & $\begin{array}{l}\text { Clinical } \\
\text { features }\end{array}$ & Associated features & $\begin{array}{l}\text { Diagnosis (not stated on } \\
\text { questionnaire) }\end{array}$ \\
\hline 1 & 40 & M & Asymptomatic & $\begin{array}{l}\text { No structural heart disease } \\
\text { or thyroid disease }\end{array}$ & $\begin{array}{l}\text { Lone atrial } \\
\text { fibrillation }\end{array}$ \\
\hline 2 & 38 & $\mathrm{~F}$ & Euthyroid & $\begin{array}{l}\text { Euthyroid following previous } \\
\text { treatment for thyrotoxicosis }\end{array}$ & $\begin{array}{l}\text { Thyroid disease } \\
\text { related atrial } \\
\text { fibrillation }\end{array}$ \\
\hline 3 & 52 & $\mathbf{M}$ & $\begin{array}{l}\text { Congestive cardiac } \\
\text { failure }\end{array}$ & $\begin{array}{l}\text { Previous myocardial } \\
\text { infarction }\end{array}$ & $\begin{array}{l}\text { Secondary atrial } \\
\text { fibrillation and } \\
\text { heart failure }\end{array}$ \\
\hline 4 & 72 & $\mathrm{~F}$ & Asymptomatic & $\begin{array}{l}\text { (Known) paroxysmal } \\
\text { atrial fibrillation; } \\
\text { no underlying heart } \\
\text { disease }\end{array}$ & $\begin{array}{l}\text { Paroxysmal atrial } \\
\text { fibrillation }\end{array}$ \\
\hline 5 & 68 & $\mathrm{~F}$ & - & $\begin{array}{l}\text { Rheumatic mitral } \\
\text { valve disease }\end{array}$ & $\begin{array}{l}\text { Secondary atrial } \\
\text { fibrillation }\end{array}$ \\
\hline 6 & 76 & $\mathrm{~F}$ & $\begin{array}{l}\text { Chest infection } \\
3 \text { weeks earlier }\end{array}$ & None & $\begin{array}{l}\text { Secondary atrial } \\
\text { fibrillation }\end{array}$ \\
\hline
\end{tabular}

decisions about anticoagulant treatment consistent with their estimation of risks, we conducted a questionnaire survey of consultant physicians in England, Wales, and Scotland.

\section{Methods}

A standard questionnaire was sent to practising consultant physicians who were identified from the Medical Register. The questionnaire included questions on the management of patients with atrial fibrillation and the role of anticoagulation, cardioversion, and antiarrhythmic treatment in patients presenting with a new diagnosis of atrial fibrillation. There were also particular questions on the anticoagulation and cardioversion preferences based upon six clinical case management scenarios, which were typical of patients presenting with either lone atrial fibrillation, paroxysmal atrial fibrillation, or atrial fibrillation associated with mitral valve disease, chest infection, or thyrotoxicosis (table 1 ).

Respondents were also asked to estimate the patient's risk of a thromboembolic event (RE) within the next 2 years if not given anticoagulation, and the patient's risk of a haemorrhagic event (RH) within the next 2 years if given anticoagulation. ${ }^{4}$ The risk estimates, independent of treatment decision, were measured using a numerical scale of 1 to 10 ; with mean percentage values quoted as mean (SD). The estimated RE was divided by the estimated $\mathrm{RH}$, this ratio ( $\mathrm{RE} / \mathrm{RH}$ ) reflecting the physician's perceived relative risk for a given patient. For example, a ratio greater than 1 would indicate that a physician thought that the chances of a RE without anticoagulants exceeded the chances of a RH with anticoagulants. The questionnaire was initially piloted among consultant physicians in our hospital.

Analysis was performed using the $\chi^{2}$ test and unpaired $t$ test as appropriate. A probability of $P<0.05$ was considered significant.

\section{Results}

A total of 500 questionnaires were sent to practising consultant physicians between May and July 1994. Completed questionnaires were obtained from 214 consultant physicians (43\%; 88 cardiologists and 126 non-cardiolo- gists), while a further four questionnaires were returned as the physicians declined to participate (an overall response rate of $44 \%$ ). Management responses were also analysed depending on whether the physicians considered themselves as practising cardiologists or non-cardiologists.

Most physicians $(47 \cdot 7 \%)$ reported that they saw one to five patients with atrial fibrillation weekly, although cardiologists tended to see more. When asked to state which was the most important factor influencing their decision of whether or not to anticoagulate a patient with atrial fibrillation, $52 \%$ of cardiologists and $40 \%$ of non-cardiologists considered that the main factor was the clinical history (that is, heart failure, valve disease, or stroke), while the next most important factors were the presence of contraindications to warfarin and information obtained from echocardiography (table 2).

When encountering a patient admitted acutely with new onset atrial fibrillation, most physicians would start anticoagulant treatment, although more cardiologists than noncardiologists would do so $\left(66 \%\right.$ v $52 \%, \chi^{2}=$ $6 \cdot 89, \quad \mathrm{P}=0.03$ ). Most cardiologists (two thirds) would start with intravenous heparin. By contrast, more non-cardiologists reported the use of either intravenous or subcutaneous heparin, or warfarin (table 2).

Most physicians would immediately introduce antiarrhythmic drug treatment, with digoxin being the most popular choice. However, more cardiologists would attempt immediate pharmacological $(39 \% v 18 \%$ of non-cardiologists, $\chi^{2}=11.3, \mathrm{df}=1, \mathrm{P}<0.001$ or later electrical $\left(86 \% v 69 \%, \chi^{2}=11 \cdot 7, \mathrm{P}=\right.$ 0.003 ) cardioversion to sinus rhythm, while non-cardiologists tended to prefer "rate control" with digoxin (table 2).

Most physicians did not continue antiarrhythmic treatment post-cardioversion, although a higher proportion of cardiologists would continue antiarrhythmic treatment (especially class III agents) (31\% v $17 \%$ of non-cardiologists, $\left.\chi^{2}=6 \cdot 1, \mathrm{df}=2, \mathrm{P}=0.04\right)$. There was also uncertainty over the use of anticoagulants post-cardioversion. Most cardiologists $(69 \%)$ would use anticoagulants postcardioversion, while only $27 \%$ of noncardiologists would do so $\left(\chi^{2}=39 \cdot 8, \mathrm{df}=2\right.$, $\mathrm{P}<0.0001)$. If anticoagulants were used, this 
was most commonly continued for 1-3 months (table 2).

Table 3 summarises the reported estimates of the patient's risk of a RE within the next 2 years if not given anticoagulation, and the

Table 2 Responses of physicians

\begin{tabular}{|c|c|c|}
\hline & $\begin{array}{l}\text { Cardiologists } \\
(n=88)\end{array}$ & $\begin{array}{l}\text { Non-cardiologists } \\
(n=126)\end{array}$ \\
\hline \multicolumn{3}{|l|}{$\begin{array}{l}\text { Number of patients with atrial } \\
\text { fibrillation seen/week }\end{array}$} \\
\hline 0 & 0 & 1 \\
\hline $1-5$ & 26 & 76 \\
\hline$>5-10$ & 33 & 39 \\
\hline$>10$ & 1 & 3 \\
\hline No answer & 1 & 3 \\
\hline \multicolumn{3}{|l|}{$\begin{array}{l}\text { Which factor most influences your } \\
\text { decision of whether or not to anticoagulate? }\end{array}$} \\
\hline Clinical history & $42 / 81(52)$ & $48 / 120(40)$ \\
\hline Contraindications & $26 / 81(32)$ & $45 / 123(37)$ \\
\hline Echocardiography & $16 / 82(20)$ & $12 / 118(10)$ \\
\hline \multicolumn{3}{|c|}{$\begin{array}{l}\text { A } 65 \text { year man is newly admitted with fast atrial fibrillation } \\
\text { (heart rate } 150 \text { beats/min, but well tolerated), with blood } \\
\text { pressure } 160 / 90 \mathrm{~mm} \mathrm{Hg} \text { and has no heart failure of structural } \\
\text { heart disease: }\end{array}$} \\
\hline \multicolumn{3}{|c|}{ Anticoagulation immediately started } \\
\hline Yes & $58 / 88(66)$ & $66 / 126(52)$ \\
\hline No & $27 / 88(31)$ & $59 / 126(47)$ \\
\hline Don't know & $3 / 88(3)$ & $1 / 126$ \\
\hline \multicolumn{3}{|l|}{ Choice of anticoagulant regime } \\
\hline Intravenous heparin & $38 / 58(66)$ & $25 / 65(38)$ \\
\hline Subcutaneous heparin $5000 \mathrm{IU}$ three times a day & $2 / 58(3)$ & $7 / 65(11)$ \\
\hline Subcutaneous heparin 25000 IU twice daily & $7 / 58(12)$ & $10 / 65(15)$ \\
\hline Warfarin & $11 / 58(19)$ & $23 / 65(35)$ \\
\hline \multicolumn{3}{|l|}{ Antiarrhythmic immediately started } \\
\hline Yes (all cases) & $64 / 87(74)$ & $101 / 126(80)$ \\
\hline Yes (if became unwell) & $11 / 87(3)$ & $10 / 126(8)$ \\
\hline No & $12 / 87(14)$ & $14 / 126(11)$ \\
\hline Don't know & 0 & $1 / 126$ \\
\hline \multicolumn{3}{|l|}{ Choice of antiarrhythmic } \\
\hline Digoxin & $50 / 87(57)$ & $91 / 126(72)$ \\
\hline Verapamil/diltiazem & 5 & 8 \\
\hline Class I agent & 8 & 2 \\
\hline Class III agent & 12 & 11 \\
\hline Other choice or no answer & 12 & 14 \\
\hline \multicolumn{3}{|l|}{ Route of administration of antiarrhythmic } \\
\hline Oral & $52 / 87(60)$ & $95 / 126(75)$ \\
\hline Intravenous & $20 / 87(23)$ & $14 / 126(11)$ \\
\hline No answer & $15 / 87(17)$ & $17 / 126(13)$ \\
\hline \multicolumn{3}{|l|}{ Objective of antiarrhythmic use } \\
\hline Rate control & $48 / 79(61)$ & $94 / 114(82)$ \\
\hline Cardioversion & $31 / 79(39)$ & $20 / 114(18)$ \\
\hline $\begin{array}{l}\text { If the patient persisted in atrial fibrillation treatment } \\
\text { no underlying cause of atrial fibrillation is present: }\end{array}$ & & \\
\hline Arrange electrical (DC) cardioversion & & \\
\hline Yes & $75 / 87(86)$ & $87 / 126(69)$ \\
\hline No & $10 / 87(11)$ & $32 / 126(25)$ \\
\hline Don't know or no answer & $2 / 87(2)$ & $7 / 126(6)$ \\
\hline Patient to be kept on antiarrhythmic & & \\
\hline $\begin{array}{l}\text { post-cardioversion } \\
\text { Yes }\end{array}$ & & $21 / 125(17)$ \\
\hline $\begin{array}{l}\text { Yes } \\
\text { No }\end{array}$ & $57 / 87(66)$ & $97 / 125(78)$ \\
\hline Don't know or no answer & $3 / 87(3)$ & $7 / 125(6)$ \\
\hline Choice of antiarrhythmic post-cardioversion & & \\
\hline Digoxin & 3 & 8 \\
\hline Verapamil/diltiazem & 1 & 2 \\
\hline Class I agent & 8 & 1 \\
\hline Class III agent & 13 & 11 \\
\hline Other choice & 2 & 1 \\
\hline How long on antiarrhythmic post-cardioversion? & & \\
\hline$\leqslant 1$ month & 7 & 2 \\
\hline$>1-3$ months & 7 & 7 \\
\hline$>3-6$ months & 6 & 4 \\
\hline$>6-12$ months & 12 & 5 \\
\hline Patient to be kept on anticoagulants & & \\
\hline $\begin{array}{l}\text { post-cardioversion } \\
\text { Yes }\end{array}$ & $60 / 87(69)$ & $34 / 126(27)$ \\
\hline No & $24 / 87(28)$ & $90 / 126(71)$ \\
\hline Don't know or no answer & $3 / 87(3)$ & $2 / 126(2)$ \\
\hline How long on anticoagulants post-cardioversion? & & \\
\hline$\leqslant 1$ month & $22 / 60(37)$ & $7 / 29(24)$ \\
\hline$>1-3$ months & $23 / 60(38)$ & $14 / 29(48)$ \\
\hline$>3-6$ months & $10 / 60(17)$ & $4 / 29$ (14) \\
\hline$>6-12$ months & $4 / 60(7)$ & $4 / 29(14)$ \\
\hline If cardioversion not attempted, would you & & \\
\hline keep patient on an antiarrhythmic? & & \\
\hline $\begin{array}{l}\text { Yes } \\
\text { No }\end{array}$ & $\begin{array}{l}48 / 87(55) \\
38 / 87(44)\end{array}$ & $86 / 126(68)$ \\
\hline $\begin{array}{l}\text { No } \\
\text { Don't know or no answer }\end{array}$ & $1 / 87(1)$ & $\begin{array}{l}40 / 126(32) \\
0\end{array}$ \\
\hline $\begin{array}{l}\text { If cardioversion not attempted, choice of } \\
\text { antiarrhythmic }\end{array}$ & & \\
\hline Digoxin & 32 & 71 \\
\hline Verapamil/diltiazem & 8 & 2 \\
\hline Class I agent & 1 & 0 \\
\hline Class III agent & 3 & 5 \\
\hline Other choice & 3 & 2 \\
\hline
\end{tabular}

Values in parentheses are percentages. patient's risk of a $\mathrm{RH}$ within the next 2 years. Non-cardiologists tended to rate the risk of thromboembolism in lone atrial fibrillation, paroxysmal atrial fibrillation, and atrial fibrillation associated with heart failure and ischaemic heart disease at a higher level than cardiologists. There was, however, general agreement among cardiologists and non-cardiologists on the risks of haemorrhage while taking anticoagulants in each of the case management scenarios. Decisions about starting anticoagulation in atrial fibrillation were usually related to the perceived relative risk of thromboembolism versus haemorrhage derived for the case management scenarios in the questionnaire, with higher mean $\mathrm{RE} / \mathrm{RH}$ values when anticoagulation was considered (tables 4 and 5).

There was general agreement between cardiologists and non-cardiologists in the perceived relative risk of thromboembolism versus haemorrhage $(\mathrm{RE} / \mathrm{RH})$ and management options for lone atrial fibrillation, paroxysmal atrial fibrillation, and atrial fibrillation associated with mitral valve disease or thyrotoxicosis (table 4).

\section{Discussion}

This study is limited by being a questionnaire survey of consultant physicians (cardiologists and non-cardiologists) and it is possible that reported practices may not reflect actual clinical management. In addition, there was only a modest response rate despite this survey being piloted and standard questionnaires being used. Nevertheless, significant trends are noted for management differences for atrial fibrillation among physicians, and also between cardiologists and non-cardiologists.

Atrial fibrillation is the commonest cardiac arrhythmia in clinical practice, and most physicians in the present survey reported that they saw at least one to five patients with atrial fibrillation weekly. Atrial fibrillation was found to be present among $6.3 \%$ of acute medical admissions to a Scottish district general hospital and was associated with a substantial morbidity. ${ }^{1}$ The presence of atrial fibrillation is associated with an increased mortality and confers a substantial risk of stroke and thromboembolism. Despite this there remains suboptimal application of standard investigations, and a low rate of introducing anticoagulant treatment and consideration of cardioversion to sinus rhythm in suitable patients. ${ }^{1-3}$ This may be a reflection of differing approaches to the management of this arrhythmia.

It is well recognised that variations in clinical practice are likely when specialists are compared with general physicians. For example, in one survey cardiologists were more likely than general physicians to recommend coronary angiography or coronary artery bypass surgery to patients with similar cardiac conditions. ${ }^{8}$ Atrial fibrillation is such a common arrhythmia, however, that practically all physicians would have had to manage a patient with atrial fibrillation at some time. Uniformity of management is therefore essential. 
Table 3 Two year risk estimates of embolism (if not receiving warfarin) and haemorrhage (if taking warfarin)

\begin{tabular}{|c|c|c|c|}
\hline \multirow[b]{2}{*}{ Case no } & \multicolumn{2}{|c|}{$R E$ and $R H$ values } & \multirow{2}{*}{$\begin{array}{l}\text { Unpaired } t \text { test } \\
\text { and } p \text { value }\end{array}$} \\
\hline & Cardiologists & Non-cardiologists & \\
\hline \multicolumn{4}{|c|}{ Risk of embolism } \\
\hline 1 & $30 \cdot 1(21 \cdot 1)$ & $38.7(23.0)^{\star}$ & $t=-2.66 ; \mathrm{P}=0.008$ \\
\hline 2 & $39.3(22.9)$ & $39.8(22.8)$ & $t=-0.16 ; \mathrm{P}=0.87$ \\
\hline 3 & $62.5(21.4)$ & $68 \cdot 2(17 \cdot 8)^{\star}$ & $t=-1.98 ; \mathrm{P}=0.05$ \\
\hline 4 & $41.6(21.9)$ & $49 \cdot 3(24 \cdot 7)^{\star}$ & $t=-2.30 ; \mathrm{P}=0.022$ \\
\hline 5 & $80 \cdot 7(15 \cdot 6)$ & $82 \cdot 3(15 \cdot 2)$ & $t=-0.96 ; \mathrm{P}=0.34$ \\
\hline 6 & $45 \cdot 8(18 \cdot 5)$ & $50 \cdot 2(21 \cdot 1)$ & $t=-1.51 ; \mathrm{P}=0.13$ \\
\hline \multicolumn{4}{|c|}{ Risk of haemorrhage } \\
\hline 1 & $17 \cdot 9(7 \cdot 9)$ & $20 \cdot 3(11 \cdot 8)$ & $t=-1.65 ; \mathrm{P}=0.10$ \\
\hline 2 & $17 \cdot 5(7 \cdot 7)$ & $19.9(11.4)$ & $t=-1.71 ; \mathrm{P}=0.089$ \\
\hline 3 & $23.7(11.9)$ & $27 \cdot 3(13 \cdot 1)^{\star}$ & $t=-1.98 ; \mathrm{P}=0.049$ \\
\hline 4 & $31 \cdot 7(17 \cdot 5)$ & $34 \cdot 1(16 \cdot 3)$ & $t=-0.95 ; \mathrm{P}=0.34$ \\
\hline 5 & $28 \cdot 6(13.6)$ & $32.0(14 \cdot 0)$ & $t=-1.68 ; \mathrm{P}=0.094$ \\
\hline 6 & $33.5(19.9)$ & $36 \cdot 4(17 \cdot 5)$ & $t=-1.03 ; \mathrm{P}=0.30$ \\
\hline
\end{tabular}

Values are percentages (means (SD)). RE, risk of thromboembolic event; RH, risk of haemorrhagic event

$\star$ Significant result.

Table 4 Management decisions by case

\begin{tabular}{|c|c|c|c|}
\hline Management options & Cardiologists & Non-cardiologists & Significance \\
\hline $\begin{array}{l}\text { Case no } 1 \\
\text { RE/RH } \\
\text { Do nothing } \\
\text { Anticoagulate, no cardioversion } \\
\text { Aspirin only } \\
\text { Anticoagulate and cardiovert }\end{array}$ & $\begin{array}{l}1 \cdot 93(1 \cdot 61) \\
5 \\
2 \\
7 \\
71\end{array}$ & $\begin{array}{l}2 \cdot 42(1 \cdot 79) \\
19 \\
3 \\
6 \\
89\end{array}$ & $\begin{array}{l}t=-1.97 ; \mathrm{P}=0.05 \\
\chi^{2}=5.54 ; \mathrm{df}=3, \mathrm{P}=0.14\end{array}$ \\
\hline $\begin{array}{l}\text { Case no } 2 \\
\text { RE/RH } \\
\text { Do nothing } \\
\text { Anticoagulate, no cardioversion } \\
\text { Aspirin only } \\
\text { Anticoagulate and cardiovert }\end{array}$ & $\begin{array}{l}2 \cdot 62(1 \cdot 98) \\
2 \\
2 \\
3 \\
74\end{array}$ & $\begin{array}{l}2 \cdot 55(2 \cdot 05) \\
10 \\
7 \\
5 \\
93\end{array}$ & $\chi^{2}=5.03 ; P=0.17$ \\
\hline $\begin{array}{l}\text { Case no } 3 \\
\text { RE/RH } \\
\text { Do nothing } \\
\text { Anticoagulate, no cardioversion } \\
\text { Aspirin only } \\
\text { Anticoagulate and cardiovert }\end{array}$ & $\begin{array}{l}3 \cdot 26(1 \cdot 93) \\
6 \\
25 \\
4 \\
52\end{array}$ & $\begin{array}{l}3 \cdot 11(1 \cdot 76) \\
13 \\
60 \\
4 \\
38\end{array}$ & $\begin{array}{l}t=0.55 ; \mathrm{P}=0.58 \\
\chi^{2}=15.59 ; \mathrm{P}=0.0014\end{array}$ \\
\hline $\begin{array}{l}\text { Case no } 4 \\
\text { RE/RH } \\
\text { Do nothing } \\
\text { Anticoagulate, no cardioversion } \\
\text { Aspirin only } \\
\text { Anticoagulate and cardiovert }\end{array}$ & $\begin{array}{l}1 \cdot 71(1 \cdot 49) \\
12 \\
35 \\
37 \\
2\end{array}$ & $\begin{array}{l}1 \cdot 80(1 \cdot 16) \\
24 \\
50 \\
33 \\
7\end{array}$ & $\chi^{2}=5 \cdot 85 ; P=0.28$ \\
\hline $\begin{array}{l}\text { Case no } 5 \\
\text { RE/RH } \\
\text { Do nothing } \\
\text { Anticoagulate, no cardioversion } \\
\text { Aspirin only } \\
\text { Anticoagulate and cardiovert }\end{array}$ & $\begin{array}{l}3 \cdot 52(1 \cdot 96) \\
2 \\
71 \\
1 \\
10\end{array}$ & $\begin{array}{l}3 \cdot 12(1 \cdot 62) \\
2 \\
100 \\
0 \\
11\end{array}$ & $\chi^{2}=1.73 ; P=N S$ \\
\hline $\begin{array}{l}\text { Case no } 6 \\
\text { RE/RH } \\
\text { Do nothing } \\
\text { Anticoagulate, no cardioversion } \\
\text { Aspirin only } \\
\text { Anticoagulate and cardiovert }\end{array}$ & $\begin{array}{l}1 \cdot 89(1 \cdot 61) \\
7 \\
11 \\
17 \\
51\end{array}$ & $\begin{array}{l}1 \cdot 68(1 \cdot 04) \\
19 \\
24 \\
30 \\
38\end{array}$ & $\begin{array}{l}t=1.03 ; \mathrm{P}=0.30 \\
\chi^{2}=12.9 ; \mathrm{P}=0.0049\end{array}$ \\
\hline
\end{tabular}

$\mathrm{RE} / \mathrm{RH}$ values are means (SD). $\mathrm{RE}$, thromboembolic event; $\mathrm{RH}$, haemorrhagic event; NS, not significant.

Table 5 Decision to introduce anticoagulation by estimated risk of thromboembolic/haemorrhagic event $(R E / R H)$

\begin{tabular}{|c|c|c|c|}
\hline \multirow[b]{2}{*}{ Case no } & \multirow[b]{2}{*}{ Anticoagulate? } & \multicolumn{2}{|l|}{$R E / R H$} \\
\hline & & Cardiologists & Non-cardiologists \\
\hline 1 & $\begin{array}{l}\text { Yes } \\
\text { No }\end{array}$ & $\begin{array}{l}2.1(1.7)^{\star} \\
0.9(1.2)\end{array}$ & $\begin{array}{l}2.6(1.9)^{\star} \\
1.6(9 \cdot 2)\end{array}$ \\
\hline \multirow[t]{2}{*}{2} & Yes & $2.7(1.9)^{\star}$ & $4 \cdot 0(2 \cdot 3)$ \\
\hline & No & $2 \cdot 3(2 \cdot 8)$ & $3.6(1.9)$ \\
\hline \multirow[t]{2}{*}{3} & Yes & $3 \cdot 3(2 \cdot 0)$ & $3 \cdot 1(1 \cdot 7)$ \\
\hline & No & $2.8(0.9)$ & $3.0(2 \cdot 3)$ \\
\hline \multirow[t]{2}{*}{4} & Yes & $2 \cdot 2(1 \cdot 8)^{\star}$ & $2 \cdot 4(1 \cdot 2)^{\star}$ \\
\hline & No & $1 \cdot 4(1 \cdot 2)$ & $1.2(0.64)$ \\
\hline \multirow[t]{2}{*}{5} & Yes & $3.6(1.9)^{\star}$ & $3 \cdot 1(1.6)$ \\
\hline & No & $2.0(0.9)$ & $3 \cdot 2(2 \cdot 1)$ \\
\hline \multirow[t]{2}{*}{6} & Yes & $2 \cdot 1(1.8)^{\star}$ & $1.9(1.0)^{\star}$ \\
\hline & No & $1.5(0.8)$ & $1.5(1.0)$ \\
\hline
\end{tabular}

Values are means $(\mathrm{SD})$

$\star \mathrm{P}<0.05$ (unpaired $t$ test)
When approaching a patient with atrial fibrillation, the decision arises of whether or not to attempt cardioversion to sinus rhythm or to achieve rate control of the arrhythmia and provide adequate thromboprophylaxis. In the present survey, the factors that most influenced the physician's decision of whether or not to anticoagulate were the clinical history (especially a history of heart failure, stroke, mitral valve disease, or hypertension), the presence of contraindications to anticoagulants, and information obtained from echocardiography. This opinion is therefore consistent with data from the stroke prevention in atrial fibrillation study ${ }^{9}$ in which the three independent clinical predictors of an increased risk of stroke were: (i) a history of hypertension; (ii) recent (within 3 months) congestive heart failure; and (iii) previous cerebrovascular event (either stroke or transient ischaemic attack). Risk stratification on the basis of these three factors allowed identification of three rates of arterial thromboembolism: $2 \cdot 5 \%$ (for patients with no risk factors), $7 \cdot 2 \% /$ year (if one risk factor was present), and $17 \cdot 6 \% /$ year (if two or three risk factors were present). ${ }^{9}$

Echocardiography is also an important investigation in patients with atrial fibrillation, especially in the assessment of risk of stroke and thromboembolism. For example, echocardiographic data from the stroke prevention in atrial fibrillation study ${ }^{10}$ showed that left ventricular dysfunction (on the two dimensional echocardiogram) and the size of the left atrium (from $\mathrm{M}$ mode echocardiograms) were strong independent predictors of later thromboembolism in patients with atrial fibrillation. In an audit of hospital management of this arrhythmia, however, this investigation was performed in only about one third of patients with atrial fibrillation, even though useful information was found in most patients undergoing echocardiography. ${ }^{1}$

Some differences were apparent in the approach to the management of a patient newly presenting with atrial fibrillation. Although most physicians would start anticoagulation, cardiologists were more likely to do so, with many favouring immediate intravenous heparin. The immediate anticoagulation would provide prophylaxis against the increased risk of thromboembolism, which is prevalent around the time of onset of atrial fibrillation. ${ }^{11-13}$ Full anticoagulation with intravenous heparin (achieving a partial thromboplastin time ratio of $2 \cdot 0-3 \cdot 0$ ) would probably be the regimen of choice, as it works rapidly, can be closely monitored, and where necessary, can be discontinued quickly; in addition, oral warfarin (if needed) could be prescribed concurrently. In comparison, administration of warfarin alone to a patient newly presenting with atrial fibrillation would require at least $72 \mathrm{~h}$ to achieve adequate anticoagulation. The use of subcutaneous heparin, especially at a dose of $5000 \mathrm{IU}$ three times daily, may be inadequate as thromboprophylaxis. ${ }^{14} 15$ By contrast, the use of subcutaneous heparin at a dose of $12500 \mathrm{IU}$ twice daily reduces mural thrombus and embolism in 
patients after anterior myocardial infarction, ${ }^{15}$ although the benefits in patients with atrial fibrillation are unknown. The anticoagulant effect with subcutaneous heparin may be inconsistent, however, dependent on the pharmacokinetics in the individual patient. ${ }^{14}$

Most physicians in this survey would also introduce antiarrhythmic treatment to a patient newly presenting with atrial fibrillation. Although most physicians favoured "rate control", more cardiologists would give antiarrhythmic treatment with the aim of immediate pharmacological cardioversion. Most cardiologists and physicians would arrange electrical cardioversion to sinus rhythm if the patient persisted in atrial fibrillation despite antiarrhythmic treatment; however, up to $25 \%$ of non-cardiologists said they would not do so. Consideration of suitable patients with atrial fibrillation for cardioversion is important, in view of the haemodynamic benefits of returning to normal sinus rhythm. In addition, the chances of successful cardioversion diminish with increasing duration of atrial fibrillation if the procedure is not considered. ${ }^{16}$

Many physicians do not routinely continue with antiarrhythmic drug treatment to maintain sinus rhythm if cardioversion is successful; however, more cardiologists than non-cardiologists would use postcardioversion antiarrhythmic treatment (especially with class III agents). There is a high risk of relapse of atrial fibrillation without antiarrhythmic drugs, with the proportion remaining in sinus rhythm ranging from $69 \%$ at 1 month to $58 \%$ at 6 months, $23 \%$ at 1 year, and $16 \%$ at 2 years. ${ }^{17}$ In the present survey, the commonest duration of continuing post-cardioversion antiarrhythmic treatment among cardiologists was for 6 months or more. Recent recommendations suggest that the use of antiarrhythmic drug treatment was most beneficial for 3 months post-cardioversion. ${ }^{18}$ However, many non-cardiologists in the present survey did not provide an answer to this question, perhaps reflecting the paucity of data on the optimal duration of continuing antiarrhythmic treatment after cardioversion to maintain sinus rhythm.

This survey also demonstrates that most cardiologists and few non-cardiologists would continue anticoagulant treatment after cardioversion to sinus rhythm, usually for 1-3 months. The finding has important implications, as the risk of thromboembolism probably continues even after successful cardioversion, as atrial mechanical function may not be restored for several weeks. ${ }^{19} 20$ However, the optimal duration of anticoagulation is, as yet, unclear. Recent recommendations by the American College of Chest Physicians include: (i) administration of warfarin for 3 weeks before elective cardioversion of atrial fibrillation of $\geqslant 3$ days' duration; (ii) continuation of warfarin for 2-4 weeks after cardioversion; (iii) administration of intravenous heparin followed by warfarin if cardioversion cannot be postponed for 3 weeks; and (iv) no anticoagulant treatment for atrial fibrillation of $<2$ days' duration or atrial flutter. ${ }^{21}$ It may be prudent to continue anticoagu- lation for longer than 4 weeks in patients with a high risk of recurrent atrial fibrillation.

The REs and RHs estimated by physicians in this survey were generally much higher than those reported for the individual conditions. The probability of stroke and thromboembolism in patients with non-valvular atrial fibrillation who are not receiving warfarin, is about $5 \% / y e a r$, while the risk of bleeding with warfarin is $1 \%$ /year. This risk is increased by the presence of structural heart disease and poor left ventricular function, as discussed earlier. ${ }^{9}$ Remarkably, physicians in this survey also tended to overestimate the risk of thromboembolism in patients with lone atrial fibrillation. In the study by Kopecky et $a l^{22}$ only $1.3 \%$ of healthy patients with lone atrial fibrillation had thromboembolism over 15 years. By contrast, data from the Framingham study $^{23}$ suggested a fivefold increase in risk for stroke in patients with lone atrial fibrillation, although patients in that study were older. ${ }^{23}$

Warfarin (as discussed earlier) reduces the risk of stroke and thromboembolism by two thirds, but increases bleeding by $53 \%^{24}$ (or $0.5 \% /$ year). As the initial risk of bleeding is fivefold smaller than the risk of embolism, prophylaxis with warfarin should be given unless it is considered that the risk of bleeding is perceived to be over six times more detrimental than the risk of thromboembolism. ${ }^{24}$ Possible factors that may increase the risk of bleeding with warfarin include: ${ }^{5}$ age, uncontrolled hypertension (defined as systolic blood pressure $>180 \mathrm{~mm} \mathrm{Hg}$ or diastolic blood pressure $>100 \mathrm{~mm} \mathrm{Hg}$ ), alcohol excess, liver disease, poor drug or clinical compliance, and bleeding lesions (especially gastrointestinal blood loss, for example, peptic ulcer disease, or previous cerebral haemorrhage), or bleeding tendency (including coagulation defects and thrombocytopenia). Concomitant use of aspirin with oral anticoagulants also increases the risk of bleeding. These factors therefore need to be taken into consideration when the risk of haemorrhage in patients given warfarin is evaluated.

The perceived relative risks of thromboembolism versus haemorrhage ( $\mathrm{RE} / \mathrm{RH})$ in different case scenarios did not differ significantly between cardiologists and non-cardiologists. However, the decision of whether or not to anticoagulate was related to risk estimates. This reassuring observation suggests that physicians make management decisions about anticoagulation of patients with atrial fibrillation based on risk estimates.

In conclusion, this survey suggests that considerable variation in the management of atrial fibrillation remains, with more cardiologists than non-cardiologists considering anticoagulation or cardioversion to sinus rhythm (and the use of antiarrhythmic and anticoagulant treatment post-cardioversion). Up to date guidelines on the management of this common arrhythmia are clearly required.

GL is recipient of the 1994 Edith Walsh and Ivy Powell Awards for cardiovascular research from the British Medical Association. We thank Dr IS Farooqi for assistance with data collection and all the clinicians who participated in this survey. 
1 Lip GYH, Tean KN, Dunn FG. Treatment of atrial fibrillation in a district general hospital. Br Heart $\mathcal{f} 1994 ; 71$ : 92-5.

2 Bath PMW, Prasad A, Brown MM, MacGregor GA Survey of use of anticoagulation in patients with atrial fibrillation. $B M \mathcal{F}$ 1993;307:1045.

3 Hendry A, Campbell AM, Campbell G, Macdonald JB, Williams BO. Antithrombotic therapy prescribed fo patients with non-rheumatic atrial fibrillation. Scott Med f 1994;39:110-1.

4 Chang HJ, Bell JR, Deroo DB, Kirk JW, Wasson JH Physician variation in anticoagulating patients with atrial fibrillation. Arch Intern Med 1990;150:83-6.

5 Lowe GDO. Antithrombotic treatment and atrial fibrillation. $B M \mp$ 1992;305:1445-6.

6 Atrial fibrillation investigators. Risk factors for stroke and efficacy of antithrombotic therapy in atrial fibrillation. Analysis of pooled data from five randomised controlled trials. Arch Intern Med 1994;154:1449-57.

7 Stroke prevention in atrial fibrillation investigators. Warfarin versus aspirin for prevention of thromboembolism in atrial fibrillation: stroke prevention in atrial fibrillation II study. Lancet 1994;343:687-91.

8 Brook RH, Park RE, Winslow CM, Kosecoff JB, Chassin MR, Hampton JR. Diagnosis and treatment of coronary disease: comparison of doctors' attitudes in the USA and disease: comparison of doctors'

9 Stroke prevention in atrial fibrillation investigators. Predictors of thromboembolism in atrial fibrillation: I Clinical features of patients at risk. Ann Intern Med 1992; 116:1-5

10 Stroke prevention in atrial fibrillation investigators. Predictors of thromboembolism in atrial fibrillation: II. Echocardiographic features of patients at risk. Ann Intern Med 1992;116:6-12.

11 Petersen P. Thromboembolic complications in atrial fibrillation. Stroke 1990;21:4-13.

12 Petersen P. Thromboembolic complications of atrial fibrillation and their prevention: a review. Am f Cardiol 1990; 65:24-28C

13 Selzer A. Atrial fibrillation revisited. $N$ Engl f Med 1982;
306:1044-5

14 Sobel BE. Thrombolysis in the treatment of acute myocardial infarction. In: Fuster V, Verstraete M, ed. Thrombosis in cardiovascular disorders. Philadelphia: WB Saunders, 1992:289-326.

15 Turpie AGG, Robinson JH, Doule DJ, et al. Comparison of high dose with low-dose subcutaneous heparin to prevent left ventricular mural thrombosis in patients with acute transmural anterior myocardial infarction. $N$ Engl f Med 1989;320:352-7.

6 Alpert JS, Petersen P, Godtfredsen J. Atrial fibrillation: natural history, complications, and management. Annu Rev Med 1988;39:41-52.

17 Dittrich HC, Erickson JS, Schneidermen T, Blacky AR Savides T, Nicod PH. Echocardiographic and clinica predictors for outcome of elective cardioversion of atrial fibrillation. Am f Cardiol 1989;63:193-7.

18 ACP/ACC/AHA Task Force Statement. Clinical competence in elective direct current (DC) cardioversion. $\mathcal{F} \mathrm{Am}$ Coll Cardiol 1993;22:336-9.

19 O’Neill PG, Puleo PR, Bolli R, Rokey R. Return of atrial mechanical function following electrical cardioversion of mechanical function following electrical cardio

20 Manning WJ, Silverman DI, Katz SE, Riley MF, Come PC, Doherty RM, et al. Impaired left atrial mechanical function after cardioversion: relation to the duration of function after cardioversion: relation to the duration

21 Dunn $M$, Alexander J, de Silva R, Hildner $F$. Antithrombotic therapy in atrial fibrillation. Chest 1989; 95:118-27S

22 Kopecky SL, Gersh BJ, McGoon MD, et al. The natura history of lone atrial fibrillation. A population-based study over three decades. $N$ Engl $f$ Med 1987;317: 669-74.

23 Brand FN, Abbott RD, Kannel WB, Wolf PF Characteristics and prognosis of lone atrial fibrillation: 30 -year follow up in the Framingham study. $7 A M A$ 1985;254:3449-53.

24 Caro JJ, Groome PA, Flegel KM. Atrial fibrillation and anticoagulation: from randomised trials to practice. Lancet 1993;341:1381-4.

\section{CORRECTION}

Autoimmunity to $a$ myosin in a subset of patients with idiopathic dilated cardiomyopathy

f H Goldman, P F Keeling, $R S$ Warraich, $M K$ Baig, $S R$ Redwood, L Dalla Libera, $\mathcal{F} E$ Sanderson, A L P Caforio, Wf McKenna (Br Heart f 1995;74:598-603).

No institutional affiliation was given for $R S$ Warraich one of the authors of this paper. Her name should have been listed under Department of Cardiological Sciences, St George's Hospital, London.
The 1996 Annual General Meeting of the British Cardiac Society will take place at the Scottish Exhibition \& Conference Centre, Glasgow from 7 to 9 May. 